\title{
A clear synthesis of Canada's medicare conundrum
}

\section{Canadian Medicare: We Need It and We Can Keep It}

Stephen Duckett and Adrian Peetoom

McGill-Queen's University Press; 2013

$\mathrm{T}$ he authors begin this engaging book with personal anecdotes that show the importance of access to health care that is free at the point of use. Such anecdotes become more important by the year, as many Canadians have lost the memory of how medical bills could destroy families and futures in the userpay world that preceded medicare. They follow these with succinct refutations of claims about medicare, such as the familiar one that Canada's system of public health insurance is not financially sustainable in the face of population aging. However, they argue that, for reasons of both cost and equity, coverage under the Canada Health Act should be expanded to include prescription drugs outside hospitals and seniors' health care at home or in a residential care facility by allied health professionals. They also offer a plain-language account of the recent history of federal-provincial financial transfers, and of the issues that will arise once the growth rate of those transfers slows after 2014.

The authors are candid about the difficulties inherent to Canadian health care and health policy. While emphasizing (as have many others) the importance of team-based primary care, they admit that "a high-quality primary care system is more goal than reality at the

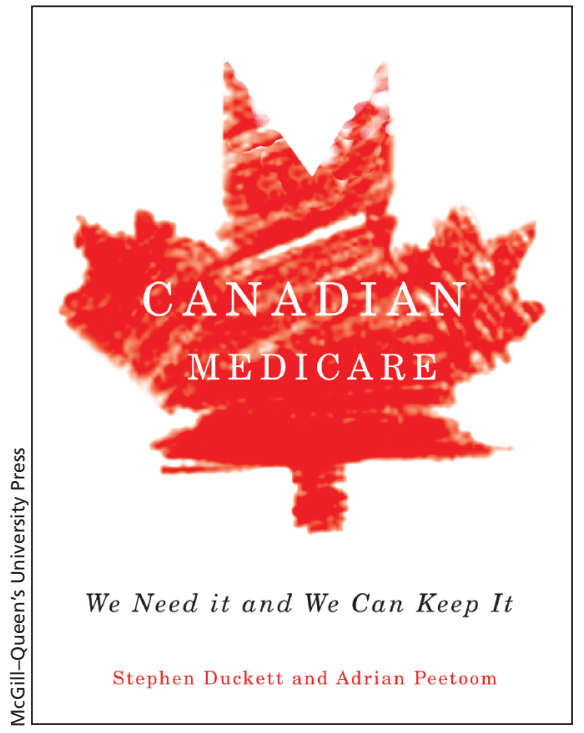

point out that other countries are well ahead of Canada in expanding the scope of practice of professionals such as pharmacists. They do not underscore, although they should, Canada's dismal comparative performance in the area of electronic health records. They do provide a useful overview of failed efforts in 2004 and 2005 to articulate meaningful national public-health goals, although their overview of the range of opportunities to improve population health by way of prevention is brief and excessively lifestyle-oriented.

Nothing is new here; the merit of this book is rather in its clear synthesis of a large body of evidence for a nonspecialist audience. Whether those who most need to read it are likely to pay the cover price is another question. At the same time, the

\section{Coverage under the Canada Health Act should include prescription drugs and home health care.}

moment." They observe that "[t]he current seniors' service system is poorly designed and riddled with discontinuities," with consequences including the continuing and costly problem of acute care hospital bed occupancy by patients who cannot be placed elsewhere. They facing the country's health systems? Or is it rather that powerful vested interests have impeded reform and shaped the health policy agenda in ways that are largely shielded from public scrutiny?

For example, provincial medical associations have repeatedly shown their ability to foreclose certain policy options and protect their economic stake in what Brian Hutchison and colleagues describe as "Canada's formidable policy legacy of physicians' autonomy and selfmanagement." Hence, such phenomena as Ontario's pay-more-and-hope approach to primary care reform, and (in the same province) continued resistance to the idea of expanding the ombudsman's remit to include hospitals and other institutions. Indeed, the interests of careproviders receive little attention from the authors, who underscore the need for greater accountability, but underestimate the difficulty of achieving it.

Further difficulties arise from the current climate of tax revolt in Canada, driven - as health economist Robert Evans has pointed out - by the determination of the wealthy to roll back the redistribution of resources that is one of the primary rationales for tax-financed public health insurance. ${ }^{2}$ A reader not already familiar with the landscape of Canadian health policy might therefore finish this book with a false sense of security. The need to preserve and expand medicare while reorganizing provision of care to address Canadians' changing needs is urgent, but the political obstacles are more formidable than the authors let on.

\section{Ted Schrecker MA}

Professor of Global Health Policy

School of Medicine, Pharmacy and Health

Durham University

Stockton-on-Tees, United Kingdom

\section{References}

1. Hutchison B, Lévesque J-F, Strumpf E, et al. Primary Health Care in Canada: Systems in Motion. Milbank Q 2011;89:256-88.

2. Evans RG. Economic Myths and Political Realities The Inequality Agenda and the Sustainability of Medicare. Vancouver (BC): Centre for Health Services and Policy Research; 2007. Available: http://medicare .ca/wp-content/uploads/2010/06/evansstudy.pdf

CMAJ 2014. DOI:10.1503/cmaj.130930 